\title{
Cannabis sativa L.: A New Promising Crop for Medical and Industrial Use
}

\author{
Dimitrios BILALIS*, Stella KARIDOGIANNI, Ioannis ROUSSIS, Varvara KOUNELI, \\ Ioanna KAKABOUKI, Antigolena FOLINA
}

Agricultural University of Athens, School of Plant Sciences, Department of Crop Science, Laboratory of Agronomy, 75 Iera Odos Str., 11855 Athens, Greece.

*corresponding author: bilalisdimitrios@gmail.com

BulletinUASVM Horticulture 76(2) / 2019

Print ISSN 1843-5254, Electronic ISSN 1843-5394

DOI:10.15835/buasvmcn-hort: 2019.0020

\begin{abstract}
The cannabis plant was discovered 10,000 years ago without its exact use being known in China and Central Asia. Equally highly interested in this plant are the pharmaceutical and construction sectors. The cultivation of Cannabis sativa $\mathrm{L}$. varieties containing more than $0.2 \%$ tetrahydrocannabinol (THC) has been legalized by the law 4523/2018 in Greece for the sole purpose of producing end-products of medicinal cannabis. The use of medicinal cannabis is important for dealing with chronic diseases. As far as cannabis cultivated for industrial use is concerned, there is a significant increase in the secondary services sector. The resulting fibers are used for the manufacture of ropes etc. Especially CBD is of great interest. Through surveys carried out by the Agronomy Laboratory of Agricultural University of Athens regarding the development of cannabis by applying geotextiles, radiation management, cannabidiol (CBD) content and tetrahydrocannabinol (THC), statistical data have been compiled for cannabis cultivation both pharmaceutical and textile. On the basis of the results, cannabis can be grown in Greece due to the weather conditions and, above all, sunshine, which is the main factor for the development of the plant.
\end{abstract}

Keywords: Cannabis sativa L., CBD, Greece, medical, THC

\section{Introduction}

Historical review

Cannabis sativa L. is a plant widely distributed all over the world (Hartsel et al., 2016). Cannabis belongs to the oil-fiber plants and the species Cannabis sativa L. was used from the Neolithic period to produce numerous products and byproducts. In Greece, hemp has been cultivated for centuries for production cords and fabrics - the first mention of it is found in $450 \mathrm{BC}$, to Herodotus. In the mid-20th century, cannabis was a major agricultural commodity cultivation and exportable product. It is characteristic that, until 1957, when cannabis cultivation was prohibited, there were seven factories operating in Greece that processed fiber to make ropes. During this period immigrants from Egypt, Cyprus and countries from the Middle
East lived moved to the port because of work (Stefanis, 1975). In 1906, the Greek government introduced customs restrictions and tax on cannabis cultivation, accepting British pressures, extinguishing the Greek grapes market. With the end of World War I the industrial cannabis was a basic agricultural crop and exportable product in 1932 (Papadopoulos, 1974).

In 2017 in Europe, the total cultivated area of cannabis for production hempseed reached 19,478 ha. and the area harvested about hemp tow waste was 11,700 ha (FAO, 2018). The last five years has seen a threefold increase in its area of cultivation Europe.

\section{Chemotype of cannabis}

C. sativa is characterized by a complex chemical composition, including terpenes, carbohy- 
drates, fatty acids and their esters, amides, amines, phytosterols, phenolic compounds, and the specific compounds of this plant, namely, the cannabinoids (Andre et al., 2016). The main ingredients of cannabis are Cannabinoids which are best-known for their healing effect and include Cannabidiol-CBD and tetrahydrocannabinol- $\Delta-9$ THC. They have been identified and isolated from hemp about 60 cannabinoid compounds, most of which are found in very little ratio (Sikora et al., 2011).

Some of the cannabinoids come from raw cannabis and others are produced after heating, some we find them more in the bud of the blooming plant or before the plant blossomed and there is also the possibility to appear only after it drying out. The characteristic fragrance in the plant comes from terpenoids.

Cannabidiol (CBD) is found in $0.5-2 \%$ in the upper $1 / 3$ of the plant and has studied for its therapeutic effect on cancer, diabetes, Alzheimer's, epilepsy etc. The THC: CBD ratio is used to characterize the cannabis under study in pharmaceutical or not (Mechtler etal., 2004). There are three cannabis chemotypes: the drug type, the fibre type and the intermediate type, which is easily distinguished by their $\Delta$-9-THC content, that represent the psychoactive constituent of the cannabis plant. The drug type is characterized by a high $\Delta$-9-THC content ( $>2 \%$ ), high in resin and is mainly found in good climatic conditions areas and sufficient sunshine. The fibre type has a low $\Delta$-9-THC content $(<0.5 \%)$ as opposed to high CBD content $(>0.5 \%)$ and is cultivated for paper, cloth and litter production. The $\Delta-9-T H C$ content in the fibre type doesn't exceed $0.03 \%$. Intermediate type characterized by the high content of $\Delta$-9-THC and CBD (>0.5\%) (Kinghorn, 2017).

Classification of cannabis by chemotype according to the below ecuation: Chemotype I (drug-type) cultivars are characterized by $\mathrm{X}$ values greater than 1 , whereas values lower than 1 are representative of chemotype III cultivars (fibertype) (Hartsel et al., 2016)

$$
X=\frac{[\mathrm{THC}]+[\mathrm{CBN}]}{[\mathrm{CBD}]}
$$

Where: CBN: Cannabinol, CBD: Cannabidiol and THC: tetrahydrocannabinol

\section{Legislation in Greece}

The cultivation of Cannabis sativa L. for medical uses was legalized in Greece in March of 2018 with a tetrahydrocannabinol (THC) content greater than $0.2 \%$. The supporting documents for set up license and operating license are valid for 5 years and 10 years, respectively. Any amendments require new supporting documents. On the basis of legislation, the cultivation will take place under enclosed conditions (greenhouse or indoor), the whole productive area must be fenced-off and there are private security guards. The quantity of propagating material introduced is limited, up to $30 \mathrm{~kg}$ of seed per hectare. Also, the greenhouse location in the field should be 1000 meters away from schools, archeological areas etc. (Regulation Gazette No. 6591, 2018). Also, according to the Law 929B/6-4-2016 fiber cannabis cultivation is permitted for cannabis varieties with a THC content $<0.2 \%$ and listed in the National \& European Community Catalog (Regulation Gazette No. 929 B, 2016).

\section{Materials and Methods}

The Agronomy Laboratory of the Agricultural University of Athens has carried out various research projects on medical cannabis and industrial hemp. Research in medical cannabis is subject to national restrictions by law, while several field experiments have been conducted in industrial hemp. The Laboratory has undertaken more than 20 projects (European, National and private sector) related to cannabis, as well as the processing of dossiers for setup enterprise units licensing by the Government. Also, we are members of editing team for the law regarding canabis cultivation.

\section{Results and discussions Climatic conditions}

Greece is characterized by predominant Mediterranean climate, with mean annual temperatures ranging from 14 to $22^{\circ} \mathrm{C}$. Most of Greece regions meet the demands of cannabis cultivation. Considering crop's requirements (temperature, photoperiod or light duration), in a case of green house facility, in order to exploit natural resources to the most, the suggested sites include the whole region from Central and West Greece to South Greece, of mainland. More particularly, the regions Thessaly, Central Greece 

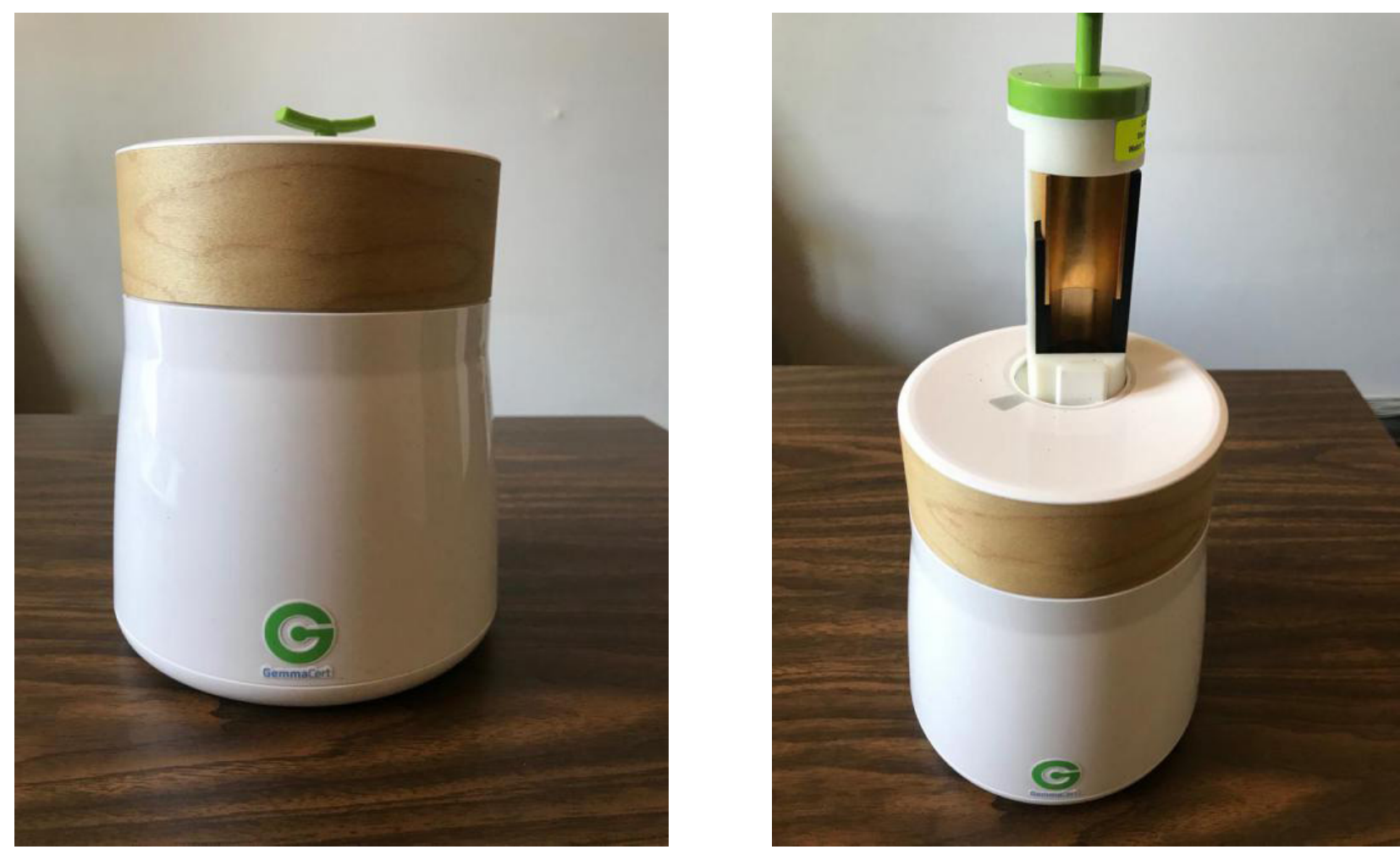

Figure 1. Device for measuring THC and CBD in cannabis flower by GemmaCert Ltd (Personal photo, archive of Prof. Dimitrios Bilalis)

and Peloponnese, are to be preferred (Folina et al., 2019).

\section{Pharmaceutical cannabis}

The medicinal cannabis is compulsorily grown in a greenhouse due to the final product concerned with a type of drug. Greenhouse cannabis crop production is based on control of the environment in such a way as to provide the conditions that are most favorable for maximum yield. The location of the greenhouse and its orientation are factors that greatly influence the production potential. Solar radiation during winter, temperature, wind and soil are needed to evaluate the suitability of a region (Mavrogiannopoulos, 2017). A region with high amount of sunlight can significantly reduce the use of technical light and therefore the cost, since the lighting constitutes the 50\% of final product cost. With regard to temperature, there are many areas in Greece where there are relatively high minimum temperatures in the winter and low maximum in the summer (Folina et al., 2019).

Through our research, we have developed greenhouse expertise in the production of pharma- ceutical cannabis. On the product line, plant growth, harvest and other grow development issues (irrigation, $\mathrm{CO}_{2}$ enrichment, lighting types (LED or HPS), duration of light, fertilization, trimming etc.). For measuring the THC and CBD content in cannabis, we use the GemmaCert device machine (Fig. 1).

\section{Industrial cannabis}

Industrial cannabis thrives in all soils but is extremely sensitive to heavy, saturated soils and soils with $\mathrm{pH}<6.0$ should be avoided. Its sowing takes place from mid-March onwards when the ground temperature is $12-14^{\circ} \mathrm{C}$ and not lower than $6-8^{\circ} \mathrm{C}$. It is proposed to be included in the program crop rotation because it has a beneficial role in yielding the next crop in particular when it comes to cereals (Amaducci et al., 2014). Fiber cannabis is very sensitive to environmental conditions such as photoperiod and temperature (day/ night temperature) (Angelini et al., 2016). Fiber hemp and its products are used in a wide range of industries and textiles (Salentijn et al., 2015) while at the same time its cultivation as an energy plant has been promoted in recent years due to the 


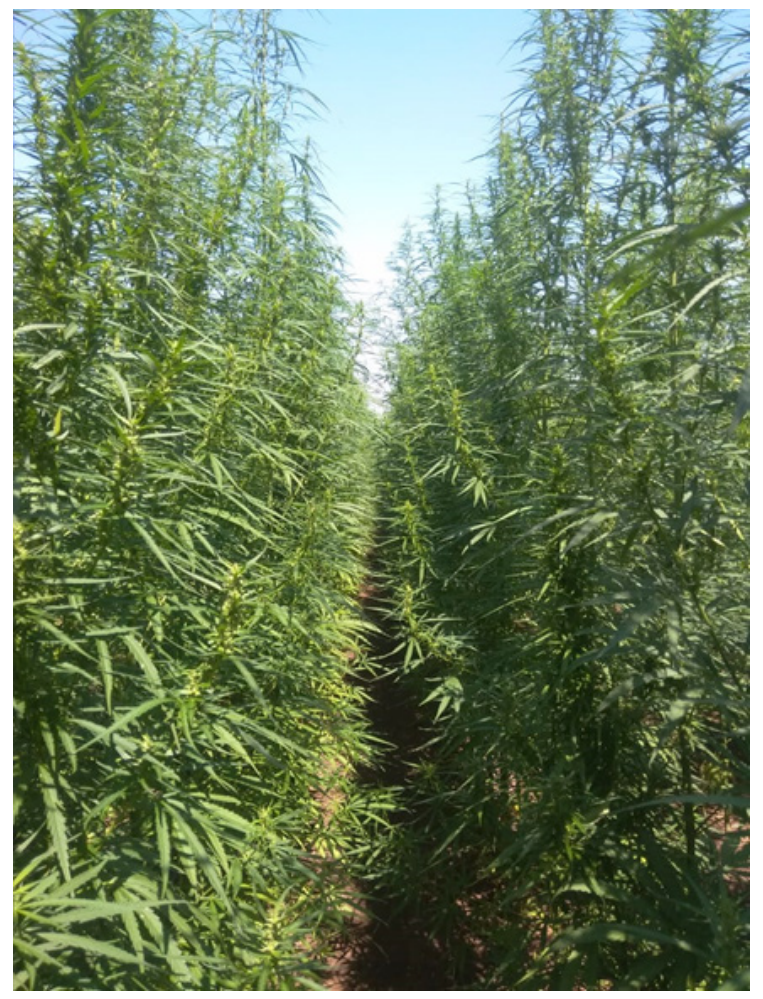

Figure 2. Industrial cannabis cultivation

(Personal photo archive of Prof. Dimitrios Bilalis)
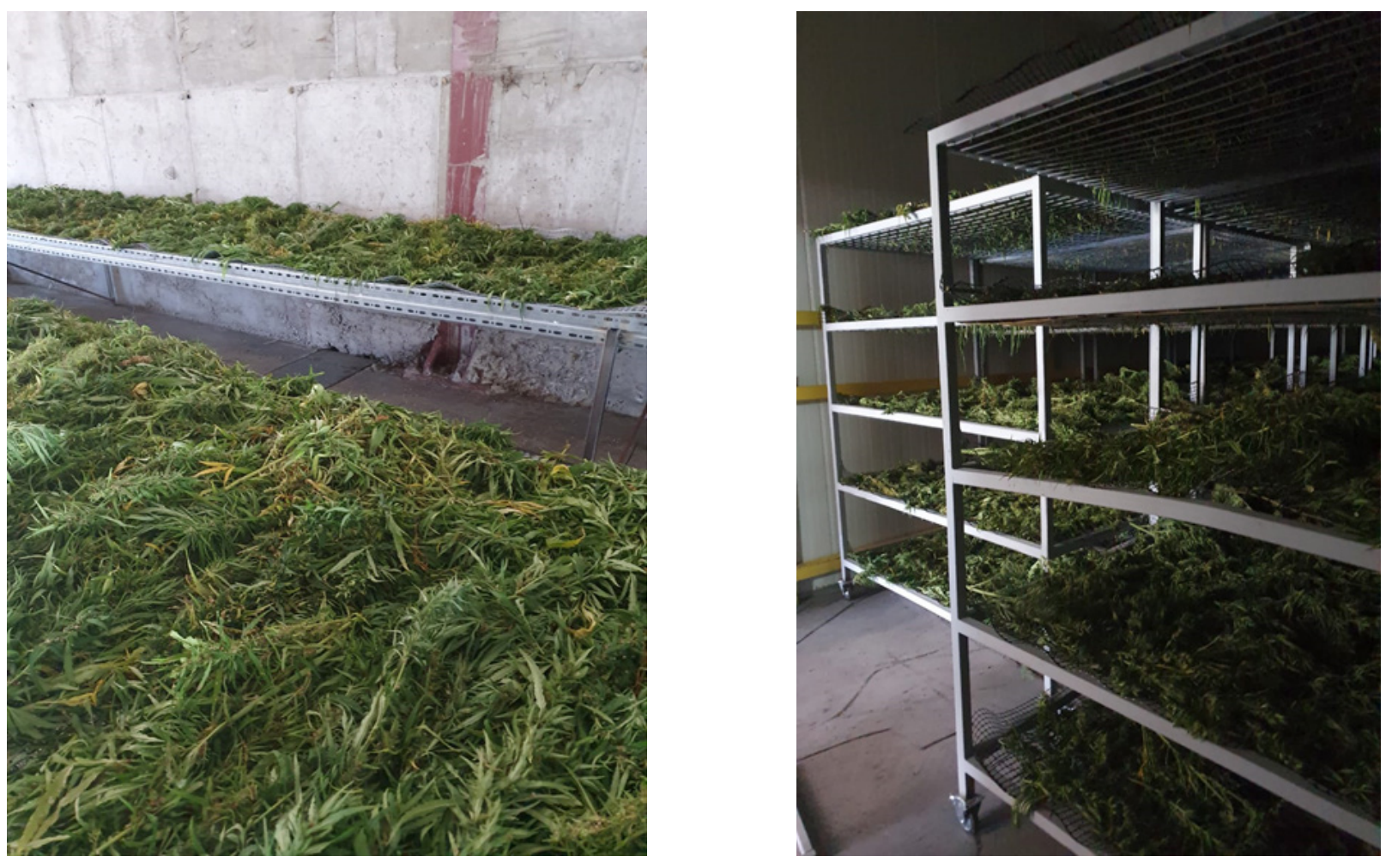

Figure 3. Processing of industrial cannabis for receiving CBD

(Personal photo archive of Prof. Dimitrios Bilalis) 
tall cellulose content (about 60\%) and low lignin content (about 7-8\%) (Cappelletto et al., 2011). Cannabis fibers are still used for the construction of insulation and building materials. Cannabis fiber constructions are used in the automotive industry as insulators and car waterproofing (Struik et al., 2000). The content of secondary metabolites such as inflorescences and leaves cannabinoids is a promising end-use area of industrial hemp (Cappelleto et al, 2011).

In industrial cannabis we have done a lot of experiments, either in the field or in the greenhouse. In a greenhouse experiment we placed a different color of geotextiles (white and black) so that we could observe different plant growth, CBD percentage and light reflection in each case. Also, a topping experiment was conducted to evaluate its effect on the concentration of CBD in cannabis buds. A major experiment was carried out in mainland Greece where industrial cannabis was cultivated in 50 plots where we sampled CBD for study and analysis (Figs. 2, 3).

\section{Conclusions}

Any discussion that was made a few years ago was considered prohibitive. The cultivation of medicinal and industrial cannabis takes place in Greece and offers tremendous opportunities for producers as well as the domestic economy. One of the most important advantages of the cannabis industry is the need for human resources, thus job creation. For example, to meet the needs of a hectare of cannabis 50 scientific or technical staff is needed. Greece has so far approved 26 enterprise licenses for the production of pharmaceutical cannabis with total setup cost more than 350 million $€$. Total application more than 72 and there are under evaluation with total set up cost more than one billion $€$. This moment 40 hectares are cultivated with industrial cannabis, both for the harvest of flowers and for the CBD oil or seed oil. Greece's competitive advantage is the high-quality industrial hemp that we can produce because of its climate, soil and geographical location. Europe is making significant imports of industrial hemp (mainly from China) to meet its increased needs. For instance, Europe imports half its seeds, while a very small proportion of its seeds are organic. There, Greece can play a very important role, as in the production of quality fibers, but also in ecological materials. Greece occupies an important place in the European Union in cannabis cultivation and is a strategic entry point into the fast-growing European territory, with a population of more than 740 million. It has both the specifications and the prospect of becoming a country producing high quantities of pharmaceutical and industrial cannabis.

\section{References}

1. Amaducci S, Scordia D., Liu FH, Cosentino SL (2014). Key cultivation techniques for hemp in Europe and China. Industrial Crops and Products, 68: 2-16.

2. Andre CM, Hausman J, Guerriero G (2016). Cannabis sativa: The Plant of the Thousand and One Molecules. Frontiers in Plant Science, 7: 19.

3. Angelini LG, Tavarini S, Candilo MD (2016). Performance of new and traditional fiber hemp (Cannabis sativa L.) cultivars for novel applications: Stem, Bark, and Core Yield and Chemical Composition. Journal of Natural Fibers, 13(2): 238-252.

4. Cappelletto P, Brizzi M, Mongardini F, Barberi B, Sannibale M, Nenci G, Poli M, Corsi G, Grassi G, Pasini P (2011). Italygrown hemp: yield, composition and cannabinoid content. Industrial Crops and Products, 13: 101-113.

5. Folina A, Roussis I, Kouneli V, Kakabouki I, Karidogianni S, Bilalis D (2019). Opportunities for cultivation of medical cannabis (Cannabis sativa L.) in Greece. Scientific Papers. Series A. Agronomy, 62(1): 293-300.

6. Food and Agriculture Organization of the United Nations (FAO). Food and Agriculture Organization Corporate Statistical Database (FAOSTAT) (2018) http://www.fao. org/faostat/en/\#data/QC Accessed 02/09/2019.

7. Hartsel JA, Eades J, Hickory B, Makriyannis A., (2016). "Cannabis sativa and Hemp", Nutraceuticals: Efficacy, Safety and Toxicity, pp. 735-754.

8. Kinghorn AD, Falk H, Gibbons S, Kobayashi (2017). Phytocannabinoids: Unraveling the Complex Chemistry and Pharmacology of Cannabis sativa. Progress in the Chemistry of Organic Natural Products, 103. Switzerland: Springer.

9. Mavrogiannopoulos GN (2017). Greenhouses, 4th edition. Athens, Greece: Stamoulis Publications (in Greek) (in Greek)..

10. Mechtler K, Bailer J, de Hueber K (2004). Variations of $\Delta-9$ THC content in single plants of hemp varieties. Industrial Crops and Products, 19: 19-24.

11. Papadopoulos DN (1974). The Cannabis, Second Edition, Athens, Greece: The Ministry of Rural Development and Food (in Greek).

12. Regulation Gazette No. 6591, Hellenic Republic (2018). Provisions for the production of final products of medical cannabis and other devices. Act No. 4523 Government Gazette No 417 March. (Regulation Gazette No. 6591).

13. Regulation Gazette No. 929 B, Hellenic Republic (2016). Terms and conditions for cultivation of cannabis varieties of Cannabis sativa L. with content-up to $0.2 \%$ in tetrahydrocannabinol, for granting the basic aid. Act No. 
1750 Government Gazette No 116136 April (Regulation Gazette No. 929 B).

14. Salentijn EMJ, Zhang Q, Amaducci S, Yang M, Trindade LM (2015). New developments in fiber hemp (Cannabis sativa L.) breeding. Industrial Crops and Products, 68: 32-41.

15. Sikora V, Berenji J, Latkovic D (2011). Influence of agroclimatic conditions on content of main cannabinoids in industrial hemp (Cannabis sativa L.). Genetika, 43(3): 449-456.
16. Stefanis C, Ballas C, Medianou D (1975). Sociocultural and epidemiological aspects of hashish use in Greece. In: V. Rubin, Cannabis and Culture. The Hague: Mouton.

17. Struik PC, Amaducci S, Bullard MJ, Stutterheim NC, Venturi G, Cromack HTH (2000). Agronomy of fibre hemp (Cannabis sativa L.) in Europe. Industrial Crops and Products, 11: 107-118. 